\title{
Formação em psicologia: o princípio da integralidade e a teoria da autopoiese
}

\author{
Psychology education: the principle of integrality and the theory of autopoiesis \\ Formación en psicología: el principio de la integralidad y la teoría del autopoiesis \\ Neuza Maria de Fátima Guareschi ${ }^{1}$ \\ Universidade Federal do Rio Grande do Sul \\ Carolina dos Reis \\ Conselho Regional de Psicologia do Rio Grande do Sul \\ Daniel Dall'Igna Ecker \\ Denise Santos Machry \\ Pontifícia Universidade Católica do Rio Grande do Sul
}

\begin{abstract}
Resumo
Neste artigo, apresentamos os resultados da pesquisa que teve por objetivo discutir os Projetos Político-Pedagógicos (PPP) dos cursos de Psicologia públicos e privados do Brasil, disponíveis nas páginas online das universidades, tomando como parâmetro o princípio de integralidade do Sistema Único de Saúde (SUS). Entendemos que esse princípio pode oportunizar uma maior aproximação da compreensão do conceito ampliado de saúde que embasa as propostas do SUS. Para isso, fundamentamo-nos na teoria da autopoiese e da enação, dos autores Maturana e Varela, para problematizar como as dicotomias produzidas nas práticas de saúde foram sendo formuladas por campos de saber, como a Medicina e a Psicologia, de maneira descolada dos contextos e das experiências de vida dos sujeitos sobre os quais intervêm. Ainda, são propostas alternativas que possam representar avanços nos modelos atuais de formação acadêmica e de atenção em saúde, que, de maneira geral, descontextualizam a experiência.

Palavras-chave: Formação do psicólogo; Princípio da integralidade; Teoria da autopoiese.
\end{abstract}

\begin{abstract}
This article presents the results of a research that aimed to discuss the political-pedagogic projects of public and private undergraduate courses in Psychology in Brazil, available on the websites of the universities. By taking the principle of integrality of Brazil's National Health System (SUS) as a standard, we understand that this principle can move us closer to the comprehension of the broadened concept of healthcare. Thus, based on both the theory of autopoiesis and the enaction concept by Maturana and Varela, we have addressed the way through which the dichotomies in healthcare practices were produced by different fields of knowledge, such as Medicine and Psychology, i.e. separately from the life contexts and experiences of the subjects upon whom they act. In addition, we have discussed some alternatives that may bring advances to the current models of academic education and healthcare, which usually decontextualize experience.

Key-words: Psychology education; Principle of integrality; Theory of autopoiesis.
\end{abstract}

\section{Resumen}

Este artículo presenta los resultados de una investigación que ha tenido como objetivo discutir los proyectos político-pedagógicos (PPP) de los cursos públicos y privados de Psicología en Brasil, disponibles en las páginas on-line de las Universidades y que toman como parámetro el principio de la integralidad de lo Sistema Unificado de Salud (SUS). Creemos que este principio pueda posibilitar una mejor comprensión del concepto ampliado de salud que sostiene las propuestas del SUS. Para eso, nos hemos fundamentado en la teoría de la autopoiesis y de la enacción de los autores Maturana y Varela para discutir cómo las dicotomías producidas en las prácticas de salud se han formulado en los campos del conocimiento, como la medicina y la psicología, así separados de los contextos y experiencias de vida de los sujetos sobre los que interviene. Por lo demás, son propuestas alternativas que pueden representar los avances en los modelos actuales de la formación académica y de atención en la salud que, en general, han descontextualizado la experiencia.

Palabras-clave: Formación del psicólogo; Principio de la integralidad; Teoría del autopoiesis.

\section{Introdução}

No ano de 2005, o Ministério da Educação e o Ministério da Saúde, por meio da Portaria Interministerial $\mathrm{n}^{\mathrm{o}}$ 2.118, firmaram parceria para

Endereço 1: Rua Ramiro Barcelos, nº 2600, Bairro Santa Cecília, Instituto de Psicologia. Universidade Federal do Rio Grande do Sul. Porto Alegre, Rio Grande do Sul, Brasil. cooperação técnica na formação e desenvolvimento de recursos humanos na área da saúde (Brasil, 2005). Essa associação é resultado de discussões prévias que se iniciaram desde a construção e o planejamento do Sistema Único de Saúde (SUS). Disposições a esse respeito podem ser encontradas na lei 8.080, que institui o SUS, na lei 9.394 de Diretrizes e Bases para a Educação Nacional (LDB), e na lei 10.861, que 
institui o Sistema Nacional de Avaliação da Educação Superior (SINAES) (Brasil, 1990; Brasil, 1996; Brasil, 2004).

No que se refere às resoluções que orientam a formulação das propostas pedagógicas do ensino superior na área da saúde, o Conselho Nacional de Saúde(CNS) estabelece que as formações profissionais devem contemplar o SUS, bem como permitir que a educação superior seja acessível a todos de forma democrática (Brasil, 2005a). Na resolução $n^{\circ} 350$ de 2005, o CNS considerou 14 cursos como aqueles que compõem a área da saúde, entre eles, está a Psicologia. A partir disso, além de contemplar as orientações do CNS, a elaboração dos Projetos Político-Pedagógicos (PPP) de cada um dos cursos da área da saúde deve ser regida pelas Diretrizes Curriculares Nacionais (DCN) (Brasil, 2013), que orientam as questões da formação para cada área específica. A Psicologia, na última reconstrução das suas diretrizes curriculares, estabeleceu a atenção à saúde como seu objetivo específico, além daqueles próprios de um egresso da educação superior. A formação em Psicologia define a atenção à saúde como participação na prevenção, promoção, proteção e reabilitação em saúde (Brasil, 2011).

Essas orientações apontam para uma demanda de formação de profissionais com uma visão holísticoecológica, tanto na produção do conhecimento, quanto na prestação de serviços, que resgatem a participação dos contextos de vida na formulação de intervenções; ainda, profissionais capazes de reconhecer as limitações de seus campos de saberes e de ampliar os referenciais para, em conjunto com a equipe, construir um repertório de ação e compreensão dos processos de saúde e adoecimento da população que lhes concerne (Machado, Monteiro \& Queiroz et al., 2007).

Diante disso, neste artigo, apresentamos os resultados de uma pesquisa que teve por objetivo colocar em análise a formação de profissionais de saúde para atuar no SUS, tomando, para tanto, o princípio de integralidade como eixo de debate. Realizamos a análise dos Projetos PolíticoPedagógicos de cursos de Psicologia do Brasil, de universidades públicas e privadas, que estão disponíveis nos sites das instituições. Elegemos a integralidade para nortear nossa discussão por entendermos que esse princípio pode oportunizar uma maior aproximação da compreensão do conceito ampliado de saúde, já que ele define a importância do cuidado integral e humanizado, a partir de ações intersetoriais, pautadas pelo trabalho de equipes transdisciplinares (Guareschi, Dhein, Reis, Machry \& Bennemannn, 2010).

Ao discutirmos o princípio de integralidade, fundamentamo-nos na noção de experiência, de Maturana e Varela (1997), a qual nos auxilia a problematizar as tentativas de formulação de um conceito que defina o que é integralidade. Para esses autores, a forma de apreensão da realidade por meio de teorias a priori revela o aspecto mutilador da produção do conhecimento. Isso acontece quando se dissociam esses conhecimentos da subjetividade presente na experiência vivida. Nesse sentido, a possibilidade de maior aproximação com uma noção integral de saúde estaria na não-dicotomização entre teoria e prática na formação acadêmica.

Por meio desses elementos, inicialmente, buscamos apresentar algumas das diversas concepções de integralidade existentes nas produções bibliográficas em Saúde Coletiva, evidenciando os impasses presentes nas tentativas de definição de um conceito único sobre integralidade. Em seguida, colocamos em discussão as práticas em saúde, tendo como base os estudos de Maturana e Varela (1997) sobre Autopoiese e Enação. A partir disso, apresentamos o percurso da pesquisa, para, então, discutirmos as questões analisadas nos PPPs, tendo como eixo de debate o princípio da integralidade. Ao final, apontamos os desafios que ainda se colocam para a formação em Psicologia no Brasil.

\section{Os princípios da Integralidade}

O art.198 da Constituição Federal estabelece como uma das diretrizes para a organização dos serviços de saúde a "atenção integral, com prioridade para as ações preventivas, sem prejuízo dos serviços assistenciais" (Brasil, 1988). Já na lei 8.080, a integralidade da assistência é estabelecida enquanto um princípio do SUS entendido "como um conjunto articulado e contínuo das ações e serviços preventivos e curativos, individuais e coletivos, exigidos para cada caso em todos os níveis de complexidade do sistema" (Brasil, 1990a).

A atenção em saúde, caracterizada pela responsabilidade de oferecer um cuidado integral, pressupõe trabalhadores capazes de reconstruir a história de vida dos usuários para além do diagnóstico e do sintoma, ativos no processo de reelaboração do sofrimento e reinvenção da vida. Para isso, é necessário capacidade para lidar com uma realidade desafiadora e complexa que não se encontra enclausurada em modelos teóricos (Dimenstein, 2001).

De acordo com a Cartilha do Aprender SUS, publicada pelo Ministério da Saúde (Brasil, 2004a), para a formação do trabalhador do SUS, a graduação pautada pela integralidade deveria ter como objetivo transformar as práticas profissionais e a própria organização do trabalho. Fala-se, portanto, em uma formação que desenvolva a capacidade de análise crítica de contextos e que problematize os saberes e as práticas vigentes. Esses dois âmbitos, da atenção e da formação, precisam ser trabalhados em consonância com as necessidades da comunidade na qual os serviços e as instituições de ensino estão inseridos, 
identificadas pela gestão setorial.

Campos (2003), ao discutir o princípio da integralidade, afirma que o ser humano é um ser biopsicossocial, que deverá ser entendido como tal por um sistema de saúde integral, voltado a promover, proteger e recuperar sua saúde. Esse modo de entender e abordar o indivíduo está baseado em uma visão holística, segundo a qual o homem é um ser indivisível que não pode ser explicado pelos seus componentes físicos, psicológicos ou sociais, considerando-os separadamente.

No entanto, Camargo Jr. (2003) atenta para um cuidado que precisamos ter ao assumirmos a integralidade como um conceito totalizador, que, embora traga uma ideia sedutora, pode produzir efeitos indesejáveis sobre os quais não refletimos. Por exemplo, se seria possível ou se realmente se almeja a atenção para a totalidade das necessidades de um ser humano, correndo o risco de cairmos em um grau sem precedentes de perda de autonomia ou até mesmo em uma medicalização também integral. Esse mesmo autor afirma, ainda, que devemos reconhecer que a integralidade é mais do que um conceito; seria, na verdade, um conjunto de tradições argumentativas que desembocam nas ideias de prevenção, promoção, proteção e reabilitação em saúde.

A referência à integralidade torna-se potente, justamente, a partir das evidências postas na contemporaneidade, com os impasses gerados pela progressiva fragmentação do saber, o que resulta em uma impossibilidade de criar um conceito único sobre a integralidade, sob pena de acabar justamente com o que ela propõe. A tentativa de fazê-lo encontra o limite de que a construção de qualquer modelo teórico é inevitavelmente redutora. Portanto, seria uma contradição a adoção de um conceito de integralidade universal descolado dos contextos de vida em que a forma de experienciar a saúde não é fragmentada, posto que a existência é única.

Nesse sentido, destacamos a importância de devolver à integralidade o lugar de ação e movimento que lhe permite operar de forma integral. Essa possibilidade, que em muitas situações lhe é retirada pelos campos de saber em nome da formalização e universalização do conhecimento, é ameaçada quando se tenta definir e generalizar, por meio de um conceito, o que seria integralidade. Esse processo, a nosso ver, apresenta-se muito mais como uma forma de totalização e homogeneização da compreensão dos fenômenos de saúde e doença do que como uma tentativa de ampliar os entendimentos sobre as ações em saúde.

\section{A Perspectiva da Autopoiese e a Abordagem Enativa}

Para devolvermos à integralidade seu potencial de ação e abrirmos possibilidades para que ela opere de forma integral, baseamo-nos nos estudos de Humberto Maturana e Francisco Varela sobre a Teoria da Autopoiese e da Enação. Utilizamos essa teoria para problematizar as dicotomias produzidas na forma como as práticas de saúde foram sendo formuladas por campos de saber, como a Medicina e a Psicologia, de maneira descolada dos contextos e das experiências de vida dos sujeitos sobre os quais intervêm. Ainda, a partir dos referenciais teóricos citados, propomos alternativas que possam representar avanços nos modelos atuais de formação acadêmica e de atenção em saúde quando estes descontextualizam a experiência.

As formulações de Francisco Varela e Humberto Maturana sobre a teoria da autopoiese partem do campo da Biologia, no intuito de responder as questões: "o que é que começa quando começam os seres vivos sobre a terra e o que se tem conservado desde então?" ou "que classe de sistema é um ser vivo?". Ao formularem uma resposta, os autores depararamse com a hipótese de que existe uma organização comum a todos os sistemas vivos, qualquer que seja a natureza de seus componentes. Essa organização tem como questão central a atuação dos seres vivos como unidades autônomas, isto é, dotadas da capacidade de reproduzir-se. Assim, a autopoiese é a denominação desse modo de organização dos seres vivos, que se distinguem de outros por sua capacidade de se autoproduzirem (Maturana \& Varela, 1997).

Embora os sistemas vivos sejam autoproduzidos, eles não são sistemas isolados; pelo contrário, são marcados pela abertura e interação com o mundo. Assim, esse modo de constituição mantém um constante processo de redefinição de suas fronteiras, de forma que o dentro está em contínua relação com o fora, por meio de um sistema de trocas permanentes, sempre procurando manter sua homeostase. Os sistemas vivos e o mundo não são dados de antemão, mas produzidos de maneira coengendrada. Isso significa que, na interação entre um organismo humano e o meio, estes se modificam mutuamente a partir dessa interação. Assim, a autopoiese é essa condição de caráter ambíguo em que os sistemas vivos são produtos e produtores de si mesmos e, ainda, possuem a capacidade de criar o mundo nesse mesmo ato de imanência (Azambuja, 2004; Sancovschi, 2007).

É essa noção do conceito de autopoiese que vai fundamentar a construção da abordagem enativa do conhecimento, desenvolvida posteriormente por Francisco Varela. Nessa perspectiva, o ato de conhecer acontece a partir das ações que estabelecemos no cotidiano (Sade, 2009). Desse modo, a formalização do conhecimento é secundária ao seu entendimento conceitual e operacional, ou seja, este que se dá na ação. Para Sade, ao formalizarmos o conhecimento, afastamo-nos da experiência do conhecer. Com o termo enação, de Varela (1988), o autor busca a preservação da relação entre a ação e o sujeito. 
Nesse entendimento, passamos a compreender que o conhecimento não depende unicamente de qualidades intrínsecas do que se conhece, mas coloca-se com base em uma história de ações diversas realizadas pelo ser no mundo. A abordagem enativa opõe-se à perspectiva representacional, em que o mundo é visto como independente e extrínseco, e parte em direção à ideia de um mundo inseparável dos processos de automodificação. Ao invés de representar um mundo independente, os sujeitos atuariam no mundo com um domínio de distinções inseparáveis entre sua estrutura incorporada e seu sistema cognitivo (Varela, Thompson \& Rosch, 2003).

$\mathrm{Na}$ enação, se estabelece um efeito circular entre ação e percepção. Ao mesmo tempo em que o sujeito interage com o mundo, ele o percebe e, no momento em que o sujeito percebe o mundo à sua volta, ele o modifica. Assim é entendida a lógica da cognição proposta pela Teoria da Enação: ação e percepção produzem-se mutuamente, assim como mundo e sujeito (Silva et al., 2010). Na visão de Varela et, al. (2003), é a experiência que constitui esse mundo próprio - é por meio da experiência que surge a fronteira entre o sujeito e o meio. Os processos cognitivos são inseparáveis de uma vivência, de uma apreensão fenomenal, dada a inseparabilidade entre corpo e mente. Para Silva et al. (2010), a compreensão do termo experiência está relacionada à concepção que se tem de cognição. Para a teoria representacional, a experiência acontece na interação com um mundo preexistente, enquanto que, para a abordagem enativa, "sujeito e mundo coemergem na experiência" (p. 85).

Ao recolocarem a experiência no cerne da forma como os seres conhecem o mundo, Varela et al. (2003) aproximam-nos da possibilidade de pensar o processo saúde/doença para além da sua apreensão conceitual. Na perspectiva dos autores, a saúde passa a ser concebida a partir do ser no mundo, e não como um conceito ou um conjunto de práticas postos a priori, deslocados dos contextos de vida e aplicáveis aos sujeitos. Essa forma de pensar a compreensão e a formulação de práticas de saúde como construídas a partir das ações que os sujeitos estabelecem no mundo não representa uma negação da concretude da doença e de seus sintomas, mas é o entendimento de que existem diferentes possibilidades de os sujeitos experienciarem tanto $\mathrm{o}$ adoecimento quanto a promoção de modos de vida saudáveis. A crítica que procuramos enfatizar neste estudo não é simplesmente que o pensamento científico seja redutor ou limitado, mas sim que é necessário situar os limites de qualquer construção teórica. Assim, um dos primeiros desafios que se apresentam à formação em Psicologia é o de realizar uma reflexão no sentido de abrir mão de certezas e permitir ao estudante e ao docente a possibilidade de experimentarem um lugar de incompletude.
Ao analisarmos os Projetos Político-Pedagógicos no que se refere à formação de profissionais para o SUS a partir do princípio da integralidade, atentamos para a forma como os cursos de graduação em Psicologia se colocam diante do desafio de construir uma formação condizente com o modelo de saúde proposto pelo SUS e com o princípio da integralidade, situando o paradoxo em que a ciência nos coloca - paradoxo esse da distância ainda existente entre a experiência e a formalização desta por meio de conceitos objetivos. Essa dicotomia, entretanto, mantém-se presente dentro dos cursos de graduação, como indicam os estudos de Guareschi et al. (2010). Propomo-no, então, a refletir sobre a forma como os estudantes de Psicologia são chamados a reconhecerem-se como produtores de saúde e, portanto, atores na produção de uma integralidade.

\section{Percursos da Pesquisa}

Para levantamento do material de discussão, realizamos o mapeamento de todos os cursos de Psicologia do Brasil presentes no cadastro da página online do MEC (Brasil, 2011a). Em seguida, fizemos um recorte no panorama geral brasileiro, selecionando apenas as universidades. Nossa escolha de estudar somente os PPPs das universidades deveu-se ao fato de estas possuírem uma trajetória acadêmica mais longa, integração entre pesquisa/ensino/extensão e produção de conhecimento na instituição (grupos de pesquisa, laboratórios, etc.). Após a seleção das universidades, buscamos os Projetos PolíticoPedagógicos dos cursos de Psicologia nas páginas online de cada instituição. Na análise dos PPPs encontrados, procuramos problematizar a proposta de formação profissional para o Sistema Único de Saúde, evidenciando as concepções de integralidade que perpassam a formação do profissional de saúde da Psicologia e as relações estabelecidas entre a aprendizagem das práticas em saúde e as experiências vividas nos processos de construção do conhecimento.

No Brasil, atualmente, existem 404 instituições de ensino superior que oferecem a formação em Psicologia. Deste número total, 357 são órgãos privados (incluindo-se Centros, Faculdades, Institutos, Fundações, Escolas de Educação Superior, Universidades e Fundações Universitárias) e 47 são públicos (Universidades e Fundações Universitárias). Na Região Norte do país, concentram-se 31 instituições com curso superior de Psicologia; na Região Centrooeste, 35; na Região Nordeste, 87; na Região Sul, 89; e, na Região Sudeste, 162 (Brasil, 2011a). Das 404 instituições do Brasil, 138 são universidades (47 públicas e 91 privadas). Destas 138 universidades, 20 disponibilizavam o projeto pedagógico online. Então, para análise, obtivemos 19 PPPs de universidades públicas e um de universidade privada. Nesses documentos, é possível conhecer o curso em questão, 
a justificativa que embasa as mudanças propostas no PPP, seus princípios, objetivos, históricos, competências gerais e perfil de egresso que se deseja desenvolver, áreas de atuação, organização do curso, estrutura curricular, núcleos e eixos estruturantes, ênfases, carga horária, atividades por semestre, lista de documentos que guiam a elaboração do PPP, assim como aspectos da estrutura física e de recursos de materiais.

\section{Projetos Político-Pedagógicos}

As reformulações dos PPPs analisados foram desenvolvidasa partirde2004, quandose estabeleceram as novas Diretrizes Curriculares Nacionais. A partir da leitura dos documentos, identificamos que as elaborações dos PPPs, de forma geral, seguem um mesmo roteiro de desenvolvimento, o que evidencia consonância com as orientações estabelecidas pelo MEC. Abaixo, descrevemos e discutimos tópicos do roteiro que são comuns a várias universidades, para então apresentarmos especificidades de alguns cursos no Brasil.

\subsection{Questões compartilhadas por todos os PPPs}

Em todos os projetos, seis pontos estão sempre presentes: 1) apresentação e justificativa; 2) histórico dos cursos; 3) bases legais dos PPPs; 4) eixos estruturantes; 5) perfil do egresso, competências e habilidades; 6) estágios e práticas.

\subsubsection{Apresentação e justificativa}

No primeiro tópico, são introduzidas ao leitor as justificativas para formulação ou modificação do projeto pedagógico do curso. A maioria das instituições aponta como justificativa para as mudanças nas estruturas curriculares a existência de documentos legais (pareceres e diretrizes) que propõem que a formação acadêmica contemple a relação entre Psicologia e Saúde Coletiva. Enfatizase que os conhecimentos da área devem estar em interface com campos afins e que o fenômeno psicológico deve ser compreendido em sua interação com aspectos biológicos, humanos e sociais de forma integral e contextualizada, em contraposição ao modelo médico/clínico historicamente predominante no Brasil. Dessa forma, construir uma formação que produza profissionais para a saúde coletiva depende da formulação de saberes e práticas que problematizem o compromisso social da universidade com as Políticas Públicas e coloquem em evidência as práticas psicológicas enquanto ações que devem estar comprometidas eticamente.

\subsubsection{Histórico dos cursos}

Já em relação ao segundo tópico, o histórico dos cursos, encontramos questões como: a descrição dos percursos efetuados para a criação do curso, o relato das mudanças significativas ao longo de sua trajetória, as preocupações em relação à formação e ao campo de atuação do psicólogo, partindo da descrição de concepções atuais para a visualização de novas perspectivas. De forma geral, grande parte dos cursos movimenta-se na busca de aproximações da Psicologia com a Política de Saúde. Além disso, os cursos têm investido em pesquisa, ensino e extensão, visando à qualificação do ensino e das práticas acadêmicas. Inclui-se, nesse percurso, a inserção dos programas Pró-Saúde, PET-Saúde e PREMUS.

A vinculação aos projetos ProUni e ReUni amplia o público que acessa o ensino superior, de modo a incluir novas perspectivas e experiências no processo de formação dos estudantes. A partir dos dados obtidos na pesquisa, percebemos que $88 \%$ dos cursos de ensino superior em Psicologia no Brasil ainda são privados, o que aponta a necessidade de ampliar ações que possibilitem o acesso democrático da população ao ensino superior, já que o ensino privado ainda é restrito apenas àqueles que conseguem pagar por ele.

Outra questão emergente na formação referese aos percursos históricos de cada curso. Sabemos que essas trajetórias estão atravessadas por diversos fatores, dentre eles, a demanda do mercado de trabalho. Nesse sentido, o investimento em determinados temas de pesquisa, ensino e extensão dá-se também devido às atualizações no próprio campo profissional. Uma das limitações que a existência de campos hegemonicamente consolidados em Psicologia acarreta é a de que estes interferem no modo como os profissionais em formação agem e se reconhecem como tal. Nessa lógica, pensamos que o histórico dos cursos, a demanda de mercado e os temas abordados em pesquisa, ensino e extensão funcionam como estímulos que produzem efeitos no modo como o estudante age e se percebe enquanto profissional da saúde. Essas composições consolidadas acerca da formação em Psicologia podem restringir a constituição de novos modos de ser psicólogo por meio da fixação em discursos cristalizados que se justificam na busca pela manutenção de uma tradicionalidade acadêmica.

Propomos uma Psicologia que seja capaz de reinventar-se, de experimentar-se por outros espaços não habitados anteriormente, que esteja aberta para as mudanças sociais e os novos modos de pensar as práticas de atenção em saúde. Para que isso ocorra, precisamos manter presentes os movimentos em que estejam colocados em questão os processos históricos da formação, suas trajetórias, transformações e intervenções no mercado de trabalho.

\subsubsection{Bases legais dos PPPs}

No terceiro elemento recorrente nos PPPs, encontramos as descrições das bases legais que norteiam sua formulação. Nesse tópico, são transcritos os principais pareceres, deliberações, resoluções, portarias e diretrizes que orientam a formulação da 
proposta pedagógica. Pensando em uma formação próxima das políticas do SUS, especificamente a partir do princípio da integralidade, destacamos os seguintes documentos, que são referências: $1^{\circ}$ ) Resolução CNE/CES no 5, de 15 de março de 2011define a atenção à saúde como uma das principais habilidades a serem desenvolvidas no estudante em formação. A formação em Psicologia define a atenção à saúde como participação na prevenção, promoção, proteção e reabilitação em saúde, segundo referenciais profissionais (Brasil, 2011); 2 ${ }^{\circ}$ ) Resolução CNS $\mathrm{n}^{\circ} 350$, de 9 de junho de 2005 - estabelece que as formações profissionais devem contemplar o SUS, assim como permitir que a educação superior seja acessível a todos de forma democrática (Brasil, 2005a).

Entretanto, ressaltamos que a existência de documentos legais que delimitem e exijam mudanças na formação acadêmica não garante uma real transformação no processo de formação dos estudantes, visto que esta também depende de professores habilitados para refletir e ensinar novas práticas. Acreditamos que formar profissionais para atuar na área da saúde coletiva em consonância com os princípios do SUS demanda mudanças no modo de se entenderem os processos de saúde e doença no espaço acadêmico.

\subsubsection{Eixos estruturantes}

Seguindo com o material de análise, temos como quarto tópico os eixos estruturantes. Como a criação de eixos aparece em todos os PPPs analisados, tornase evidente que essa prática de categorização de assuntos preestabelecidos, que embasa e estabelece os temas importantes para a construção da formação em Psicologia no Brasil, é uma ação legitimada e recorrente nas universidades estudadas. Apresentado de diferentes maneiras, esse tópico descreve o alicerce epistemológico da estrutura curricular. A partir da delimitação de temas centrais, denominados de eixos estruturantes, definem-se as atividades a serem realizadas pelo estudante (estágios, práticas, trabalhos), bem como as disciplinas prioritárias na formação em Psicologia. $O$ estabelecimento desses eixos segue as diversas orientações de requisitos legais e normativos estipulados pelo MEC/INEP no que se refere à construção curricular do ensino superior (Brasil, 2013). Dessa forma, os eixos estruturantes visam a estabelecer uma base homogênea para a graduação em Psicologia como campo de conhecimento e de atuação no Brasil, atentando para que o estudante, como cita um dos documentos, identifique e empregue corretamente, com precisão e coerência, conceitos da Psicologia (Brasil, 2004a). A partir desses eixos, cada curso estabelece as ênfases curriculares que desenvolverá na sua proposta curricular.

Dentre todos os 20 PPPs analisados, percebemos que as três ênfases que mais se repetem são: a ênfase do social, do desenvolvimento e da clínica. Das três principais ênfases, apenas a denominada de "social" prioriza estudos na área das Políticas Públicas (de educação, saúde, segurança, trabalho, etc.) e propõe a formação de profissionais que produzam ações de atenção em saúde pensadas a partir dos princípios do SUS, com destaque nas Políticas de Humanização. Essa ênfase prioriza temas relacionados à Psicologia, às instâncias de controle social e à formação para profissionais da rede de saúde mental (CAPS, Residenciais Terapêuticos e outros equipamentos), ressaltando a importância de problematizar a dimensão política da Psicologia. Nessa temática, o estudante é incitado a transpor as tradicionais dicotomias entre teoria e prática, individual e coletivo, público e privado, com o intuito de questionar os modos como os sujeitos se constituem dentro de determinados espaços, tempos e práticas.

A construção de uma formação pautada por temas homogeneizados produz discursos e práticas psicológicas de forma unificada, tendo como principal objetivo, como citam os PPPs, "a inserção dos profissionais no mercado de trabalho". A nosso ver, a produção de discursos uniformes abre espaço para possíveis práticas estereotipadas e descontextualizadas das situações/sujeitos em que são demandadas práticas de atenção em saúde. É possível visualizar esse tipo de lógica na segunda ênfase, a do desenvolvimento, na qual se priorizam ações em saúde que avaliam, previnem e realizam intervenções, tendo padrões globais e generalizantes do comportamento humano como base de referência.

Sugere-se que as ações em saúde sejam produzidas a partir do ser no mundo, e não como conceitos ou um conjunto de práticas postas a priori, deslocadas dos contextos de vida e aplicáveis aos sujeitos de forma mecânica e generalizada. Sade (2009) demonstra que as produções acadêmicas nos levam ao comprometimento ético/político de compreender que cada mundo é um mundo. Segundo o autor, a tendência das diferentes abordagens é a de focar em determinado aspecto do sujeito ou da situação como forma de interpretar a conjuntura emergente. De acordo com Sade (2009), o conhecimento que produzimos não são provas da verdade, mas verdades do nosso mundo, que é apenas um entre tantos.

Nesse sentido, surgem alguns desafios à formação em Psicologia: $1^{\circ}$ ) que ela possa entender o processo de formação como uma prática contínua na qual o profissional estará sempre experimentando sentimentos de incompletude em relação aos fundamentos teóricos; $2^{\circ}$ ) que ela diferencie tentativas de "dominação teórica", em que se tenta encaixar o sujeito em explicações racionais a priori, e práticas de "reflexão teórica", em que a teoria surge apenas como mais uma ferramenta entre outras possíveis; $3^{\circ}$ ) que ela tente escapar de ações que visem a enquadrar 
os sujeitos em mundos previamente estabelecidos, na busca de garantir a manutenção de um status de verdade para a teoria.

\subsubsection{Perfil do egresso, competências e habilidades}

O penúltimo tópico refere-se ao perfil do egresso. Nessa parte dos documentos, estão descritos o perfil do profissional almejado e as competências e habilidades que devem ser desenvolvidas durante a graduação. Além disso, cada curso elege as habilidades prioritárias que um estudante de Psicologia deve possuir. Dentre as diversas competências e habilidades elegidas pelos cursos do Brasil, as que mais se aproximam das propostas das políticas do SUS são:

$1^{\circ}$ ) Atenção integral à saúde: o estudante é estimulado a conhecer a Política de Saúde e os princípios que a embasam. $\mathrm{O}$ atendimento aos sujeitos é pensado pela lógica do SUS, tendo como norteadores os princípios da integralidade, da equidade, da descentralização e da participação social. Em 16 cursos, objetiva-se que o estudante seja capacitado a entender a saúde como sinônimo de promoção de vida. Dessa forma, quando profissional, deverá estar apto a desenvolver ações de prevenção, promoção, proteção e reabilitação em saúde nos campos da atenção em saúde, da educação, do trabalho e da assistência social;

$2^{\circ}$ ) Respeito aos princípios éticos nas relações humanas: o estudante deve estar capacitado a promover a cidadania e o protagonismo social junto às comunidades com as quais trabalha. Deve estimular intervenções que atendam às demandas sociais;

$3^{\circ}$ ) Trabalho em equipes multiprofissionais: o aluno deve desenvolver a competência para o trabalho interdisciplinar, priorizando ações de cooperação e interlocução entre as áreas envolvidas. O estudante deve integrar planejamento e gestão, estimulando a capacidade criativa da equipe;

$\left.4^{\circ}\right)$ Produção de conhecimento científico: a formação deve capacitar profissionais para a reflexão crítica e contextualizada historicamente acerca dos conhecimentos produzidos pela Psicologia.

Embora a construção do perfil profissional descrito nos PPPs possa ser abrangente e condizente com as demandas apresentadas à formação de profissionais para atuarem junto ao SUS, é preciso estar atento para que a delimitação de perfis profissionais não restrinja a construção de novos modos de ser profissional de saúde. Chamamos atenção aqui para o fato de que a formulação de perfis, ainda que bastante amplos, jamais poderá dar conta das multiplicidades de situações a serem enfrentadas no cotidiano de trabalho; nesse sentido, ela não pode ser limitadora da capacidade dos sujeitos de desenvolverem práticas inventivas.

\subsubsection{Estágios e Práticas}

Nesta etapa do texto, como último ponto de discussão, apresentamos como os estágios e práticas são descritos nos PPPs. Nas análises, todos os cursos de Psicologia do Brasil estabelecem que o estudante deve passar por práticas e estágios obrigatórios para obter o diploma de graduado, assim como orientam as Diretrizes Curriculares Nacionais. Nos PPPs, os estágios e práticas são descritos de acordo com os critérios de cada curso, mas, de forma geral, todas as universidades relatam as competências que os estágios e práticas devem desenvolver. Além disso, são estabelecidas as principais áreas temáticas de formação que o estudante deve vivenciar para tornar-se psicólogo. Diversos cursos oferecem a possibilidade de o estudante optar por alguma ênfase mais ao final de sua formação. As ênfases são temáticas específicas (por exemplo, ênfase em trabalho, ênfase em educação, ênfase em saúde) das quais o estudante escolhe uma de seu interesse com o objetivo de aprofundar seus estudos em determinada área de conhecimento. Ao escolher uma ênfase, ele passa a priorizar aulas que possuam teorias e temáticas específicas. Alguns dos cursos oferecidos possibilitam o estágio ou prática na área das Políticas Públicas, favorecendo a aproximação dos estudantes com o SUS. A principal justificativa presente nos PPPs que embasa as orientações sobre os estágios e práticas é a de que esse contato proporcionaria ao estudante a possibilidade de ver a "teoria na prática". Com essa justificativa, evidencia-se que a teoria é percebida como algo dissociado da prática.

Além disso, as ênfases curriculares propostas pelos cursos mantêm os conteúdos acadêmicos também dissociados e colocam o estudante no encargo de aderir ou não a determinada teoria. Os locais de estágio são definidos pelas universidades, que assim regulam o que deve ou não ser considerado como prática do psicólogo. Esse tipo de regulamentação interfere no modo como a Psicologia se insere ou se mantém distante de determinados espaços/temáticas. A problemática, nesse caso, não é entender como as práticas em Psicologia foram se configurando ao longo da história, mas sim como o presente é capaz de produzir rupturas nos antigos hábitos. Kastrup (1998) utiliza-se dos estudos de Maturana e Varela para exemplificar que esses autores denominam o processo de ruptura por meio do conceito de breakdown. A noção de breakdown surge, antes de tudo, como uma capacidade de invenção de problemas, de produção de trincas no fluir das condutas estereotipadas. Assim, buscar fissuras nas práticas psicológicas, produzir quebras nas ações e interpretações legitimadas é essencial para que o psicólogo amplie seu campo de prática e contemple a diversidade de sujeitos e realidades que se produzem constantemente no mundo.

\subsection{Divergências e Especificidades nos PPP}

Como ponto de quebra neste nosso processo de 
análise sobre a formação brasileira em Psicologia, encontramos algumas especificidades em três cursos estudados. No curso da Região Norte, a elaboração do PPP é efetuada a partir de elementos característicos da região em que o curso se situa. $\mathrm{Na}$ apresentação da proposta pedagógica, é enfatizado o diferencial da formação oferecida: a construção de conhecimento científico da instituição leva em consideração a realidade específica da região. Assim, o curso define como um de seus princípios norteadores a "ênfase à realidade amazônica", na qual os fenômenos sociais estudados seriam entendidos dentro de uma complexidade política, cultural e econômica característica do contexto amazônico.

Já na proposta de formação do curso do nordeste, o desafio apresentado é compatibilizar a tradição do campo científico em Psicologia com uma formação orientada para atender a região do semiárido nordestino. Além do reconhecimento da diversidade local, a proposta pedagógica do curso em questão situa o leitor, descrevendo as características locais (inclusão da região no Polígono das Secas, descrição das prolongadas estiagens, do sistema econômico de agronegócio, da forte exportação de mercadorias locais, etc.), para então compor sua estrutura a partir dessas singularidades. Além disso, é levada em conta a interferência, por exemplo, do Polo Petrolina e Juazeiro, para discutir seu impacto no contexto regional e fundamentar que os profissionais formados no curso devem ser estimulados a promover saúde e qualidade de vida, atentando para as oportunidades e demandas que surgem a partir dessas referências. O PPP do curso declara: "a relação teoria-prática será contemplada a partir de uma concepção de que o conhecimento se constrói na relação com o outro e com o mundo, num pensar articulado e voltado para um saber ser e um saber fazer".

Finalizando a exposição do material analisado, temos o curso da Região Sudeste, que apresenta o diferencial de possuir um mesmo PPP para orientar cinco cursos da área da saúde: Nutrição, Fisioterapia, Educação Física, Terapia Ocupacional e Psicologia. A ideia central dessa proposta é a de que a prática profissional em conjunto deve ser o eixo norteador do projeto pedagógico. Assim, a sugestão educacional desse curso é que a educação para o trabalho em equipe e para a integralidade no cuidado parta de uma formação interprofissional. Dessa forma, o curso também estabelece eixos estruturantes, mas, diferentemente dos eixos relatados nos outros PPPs de Psicologia analisados (relembrando: eixo do social, do desenvolvimento e da clínica), os quatro aqui apresentados são: $1^{\circ}$ ) $\mathrm{O}$ ser humano em sua dimensão biológica; $2^{\circ}$ ) O ser humano em sua inserção social; $3^{\circ}$ ) Aproximação ao trabalho em saúde; $4^{\circ}$ ) Aproximação a uma prática específica em saúde.

Esses eixos norteiam a formulação de todo o projeto pedagógico e evidenciam o novo cenário social de implementação do SUS, que abre então para mudanças no ensino. Apesar de esse PPP ser descrito para os cinco cursos, em um momento do documento, cada curso apresenta sua especificidade, mas, mesmo na Psicologia, predominam disciplinas de Psicologia aplicada à área da saúde, como, por exemplo, Legislação em Saúde Mental, Psicologia na Atenção Primária à Saúde, Psicologia na Atenção Secundária à Saúde, Psicologia na Atenção Terciária à Saúde e Introdução à Pesquisa em Psicologia e Saúde.

\section{Questões para a formação acadêmica em Psicologia}

Após a análise dos materiais, entendemos que os Projetos Político-Pedagógicos, enquanto reflexão de uma posição ética e política dos cursos de graduação em Psicologia, devem estar em constante transformação. É por meio da experiência que mundo, sujeito e meio se constituem. Frente a isso, surge o desafio de abrirmos mão de uma ciência que limita a compreensão dos processos de saúde (Kastrup, 2008), para pensarmos em uma produção de conhecimento que reconhece a complexidade como necessária a esse entendimento. Esses movimentos são essenciais para construirmos novas práticas de ensino que contemplem uma formação em saúde orientada para as políticas do SUS, especialmente, que contemplem o princípio da integralidade.

Além disso, o processo de formação em Psicologia deveria apontar não somente para a construção de novos posicionamentos, mas para a possibilidade de o estudante, durante a formação acadêmica, poder transitar entre diferentes níveis e formas de apreensão da realidade, tendo como referencial os acontecimentos que o mobilizam a intervir. A questão é recolocar a experiência no cerne do conhecimento, tornando os sistemas teóricos meras ferramentas para o encontro entre o estudante e o usuário da rede de saúde (Czeresnia, 2003). Portanto, o conhecimento sobre saúde, a partir do cuidado integral, emerge da experiência construída no encontro - encontro que, se fundamentado em um paradigma de ciência que prioriza a organização didática de uma vida abstrata, se distanciará dos modos singulares de experienciar saúde e doença dos sujeitos concretos. O que se busca, portanto, não é uma formação que se faça totalizadora, mas integral.

\section{Referências}

Azambuja, R. S. de. (2004). Autopoiese e Ciência. Cultura Homeopática, 3(8), São Paulo, 13-15.

Brasil. (1988). Presidência da República. Casa Civil. Constituição Federal. Brasília.

Brasil. (1990). Ministério da Saúde. Lei n 8.080 de 19 de setembro de 1990. Brasília.

Brasil. (1990a). Ministério da Saúde. ABC do SUS. Diário Oficial da União, Brasília. 
Brasil. (1996). Presidência da República. Casa Civil. Subchefia para Assuntos Jurídicos. Lei nº 9.394, de 20 de dezembro de 1996. Brasília.

Brasil. (2004). Presidência da República. Casa Civil. Subchefia para Assuntos Jurídicos. Lei $\mathrm{n}^{\circ} 10.861$, de 14 de abril de 2004. Brasília.

Brasil. (2004a). Ministério da Saúde. Aprender SUS: o SUS e os cursos de graduação da área da saúde. Brasília.

Brasil. (2005). Ministério da Educação. Portaria Interministerial $\mathrm{n}^{\circ} 2.118$ de 3 de novembro de 2005. Brasília.

Brasil. (2005a). Ministério da Educação e Cultura. Conselho Nacional de Saúde. Resolução no 350, de 09 de Junho de 2005. Diário Oficial da União, Brasília.

Brasil. (2011). Câmara de Educação Superior do Conselho Nacional de Educação. Resolução No 5, de 15 de março de 2011. Diário Oficial da União, Brasília.

Brasil. (2011a). Ministério da Educação e Cultura. Instituições credenciadas. Diário Oficial da União, Brasília.

Brasil. (2013). Ministério da Educação. Diretrizes Curriculares Nacionais- Cursos de Graduação. Brasília.

Brasil. (2013a). Ministério da Educação. ProUni. Apresentação. Brasília.

Brasil. (2013b). Ministério da Educação. Programa de Apoio a Planos de Reestruturação e Expansão das Universidades Federais (Reuni). Brasília.

Camargo, J. K. R. de. (2003). Um Ensaio sobre a (In)Definição de Integralidade. (In). Pinheiro R. \&Mattos, R. P. (Orgs.). Construção da Integralidade: cotidiano, saberes e práticas em saúde. Rio de Janeiro: IMS/UERJ - CEPESC - ABRASCO, 35-44.

Campos, C. E. A. (2003). O desafio da Integralidade segundo as perspectivas da vigilância da saúde e da saúde da família. Ciência \& Saúde Coletiva, 8(2), Rio de Janeiro, 569-584.

Czeresnia, D. (2003). O conceito de saúde e a diferença entre prevenção e promoção. (In).Czeresnia, D.\&Freitas, C. M. (Orgs.). Promoção de Saúde: conceitos, reflexões, tendências. Rio de Janeiro: Ed. Fiocruz, 39-53.

Dimenstein, M. (2001). O psicólogo e o compromisso social no contexto da saúde coletiva. Psicologia em Estudo, 6(2), Maringá, 57-63.

Guareschi, N; Dhein, G; Reis, C; Machry, D; Bennemannn, T. (2010). A Psicologia e a Formação do Profissional da Saúde para o SUS: um estudo a partir dos currículos de Psicologia do Rio Grande do Sul. In: Guareschi, N;Scisleski, A; Reis, C;Dhein, G;Azambuja, M. (Orgs.). Formação, Política e Produção em Saúde. Porto Alegre: EDIPUCRS, 29-53.

Kastrup, V. (1998). A cognição contemporânea e a aprendizagem inventiva. Arquivos Brasileiros de Psicologia, 49(4), 108-122.

Kastrup, V. (2008). Autopoiese e Subjetividade: sobre o uso da noção de autopoiese por Gilles Deleuze e Felix Guattari. (In). Kastrup, V;Tedesco, S. \&Passos, E. (Orgs.). Políticas da Cognição. Porto Alegre: Sulina. 46-63.

Machado, M. de F; Monteiro, E. M.\& Queiroz, D. (2007). Integralidade, formação de saúde, educação em saúde e as propostas do SUS - uma revisão conceitual. Ciência \& Saúde Coletiva,12(2), Rio de Janeiro, 335-342.

Maturana, H.\& Varela, F. (1997). De Máquinas e Seres Vivos - Autopoiese, a organização do vivo. Porto Alegre: Artes Médicas.

Sade, C. (2009). Enação e Metodologias de Primeira Pessoa: o reencantamento do concreto das investigações da experiência. Informática na Educação: teoria e prática,12(2), Porto Alegre, 4558.

Sancovschi, B. (2007). Sobre a Noção de Representação em S. Moscovici e F. Varela. Psicologia \& Sociedade, 19(2), Florianópolis, 7-14.

Silva, A. do E., Passos, E., Fernandes, C. V. A., Guia, F. R., Lima, F. R. de., Carvalho, J. F., Barros, L. M. R. \& Sade, C. (2010). Estratégias de Pesquisa no Estudo da Cognição: o caso das falsas lembranças das investigações da experiência. Psicologia \& Sociedade, 22(1), Florianópolis, 84-94.

Varela, F. (1988). Conhecer: as ciências cognitivas tendências e perspectivas. Lisboa: Instituto Piaget.
Varela, F. (1992). The reenchantment of the concrete. Revista Zone, (6), 320-338.

Varela, F; Thompson, E.\&Rosch, E. (2003). A Mente Incorporada: ciências cognitivas e experiência humana. Porto Alegre: Artmed.
Recebido: 05/09/2013

Última revisão: 20/11/2013 Aceite final: $28 / 11 / 2013$ 
Sobre os autores:

Neuza Maria de Fátima Guareschi - Professora/Pesquisadora, Bolsista Produtividade em Pesquisa CNPq 1C, Coordenadora do Grupo de Pesquisa Estudos Culturais e Modos de Subjetivação dentro do Núcleo e-politcs - Estudos em Políticas e Tecnologias Contemporâneas de Subjetivação - Coordenadora do Programa de Pós-Graduação em Psicologia Social e Institucional do Instituto de Psicologia da Universidade Federal do Rio Grande do Sul.

E-mail: nmguares@gmail.com

Carolina dos Reis - Psicóloga, Doutoranda no Programa de Pós-Graduação em Psicologia Social e Institucional (PPGPSI) do Instituto de Psicologia da Universidade Federal do Rio Grande do Sul, vinculada ao Núcleo e-politcs - Estudos em Políticas e Tecnologias Contemporâneas de Subjetivação. Assessora Técnica no Centro de Referência Técnica de Psicologia e Políticas Públicas (CREPOP) no Conselho Regional de Psicologia do Rio Grande do Sul (CRP/RS).

Daniel Dall'Igna Ecker - Graduando em Psicologia pela Pontifícia Universidade Católica do Rio Grande do Sul, Bolsista de Iniciação Científica (CNPq) no Grupo de Pesquisa Estudos Culturais e Modos de Subjetivação dentro do Núcleo e-politcs - Estudos em Políticas e Tecnologias Contemporâneas de Subjetivação do Programa de Pós-Graduação em Psicologia Social e Institucional do Instituto de Psicologia da Universidade Federal do Rio Grande do Sul.

Denise Santos Machry - Psicóloga pela Pontifícia Universidade Católica do Rio Grande do Sul (PUCRS). Residente do Programa de Residência Integrada em Saúde do Grupo Hospitalar Conceição - Ênfase Saúde da Família e Comunidade. 